
\title{
Reseacch S Suare \\ Diagnosis of Staphylococcus Aureus in Non-treated Blood Using Mercury Immobilized on a Carbon Nanotube Biosensor.
}

Suwyoung Ly ( $\sim$ suwyoung@snut.ac.kr)

Seoul National University https://orcid.org/0000-0002-1226-9520

KwangJin Choi

Sahmyook University

Ji Hyun Kim

Sahmyook University

Kyung Lee

Seoul National University of Technology: Seoul National University of Science and Technology

\section{Research Article}

Keywords: Staphylococcus aureus, Molecular probe, voltammetry, assay

Posted Date: February 9th, 2022

DOI: https://doi.org/10.21203/rs.3.rs-747104/v1

License: (a) (i) This work is licensed under a Creative Commons Attribution 4.0 International License. Read Full License 


\section{Abstract}

\section{Background}

Staphylococcus aureus bacteria is a ubiquitous Gram-positive microorganism that causes of infections related to the sudden infant death syndrome

\section{Objectives}

To identify an effective diagnostic method for Staphylococcus aureus (SA), a voltammetric sensing probe was sought using mercury immobilized on a carbon nanotube sensor (MCN).

\section{Study design}

The voltammetric MCN conditions were optimized through stripping and cyclic voltammetry. Diagnostic electrolyte was used on non-treated blood sera as an electrolyte solution.

\section{Results}

The optimum cyclic and stripping analytical working range was $0.5-4.0 \mathrm{ml}\left(3 \times 10^{2} \sim 5 \times 10^{2} \mathrm{CFU} / 0.5 \mathrm{~mL}\right) \mathrm{SA}$. The statistic relative standard deviation of $0.1-\mathrm{mL} \mathrm{SA}$ was observed to be $0.0078(n=5)$.

\section{Conclusions}

Using the optimum parameters, diagnostic application was performed in the direct assay of SA in nontreated human blood and patient sera.

\section{Background}

Staphylococcus aureus is a ubiquitous Gram-positive microorganism bacteria ${ }^{[1]}$ and a food poisoning agent ${ }^{[2]}$ that causes a variety of infections related to the human toxic shock syndrome and sudden infant death syndrome ${ }^{[3]}$. Advanced diagnostic detection methods were recently developed, including one-step immunochromatographic assay ${ }^{[4]}$, gold-nanoparticle-based immunochromatographic assay ${ }^{[5]}$, real-time nucleic-acid-sequence-based amplification assay [6], reverse-transcription PCR assay [7], real-time PCR assay [8], enzyme-linked immunosorbent assay [9], and multiplex PCR/RPLA identification ${ }^{[10]}$. Some of these basic methods, however, depend on PCR amplification, electric separation, and spectric adsorption and require electric or other detection systems. Voltammetric methods, on the other hand, do not need complicated separation, amplification, and detection systems.

\section{Objectives}

In this study, an attempt was made to simplify the modification probe and to directly conduct non-treated blood assay for SA diseases, which is fast, sensitive, and does not require any preparation. Moreover, in 
this study, mercury immobilized ${ }^{[11]}$ on a carbon nanotube structure ${ }^{[12]}$, whose carbon surface has catalytic effects [13], a large surface area, and high electrical conductivity [14], and whose probe can react to the SA target, was sought. Redox voltammograms were obtained via the SW stripping and cyclic voltammetric reaction. The analytical parameters were optimized, and the results achieved low detection ranges for the SA target. The developed methods can be applied in the direct assay of non-treated blood sera, and the final results can be used for organ monitoring, in-vivo diagnosis, and other assays requiring SA detection.

\section{Study Design}

\subsection{Instrument, reagent, and MCN preparation}

Diagnostic circuits were carried out using a BVA 2 voltammetric workstation from the authors' institute. The carbon nanotube probe was obtained from Nanotech Co., Ltd., Choong Nam 330-816, South Korea (by catalytic CVD; outside diameter: 15-40 nm; length: 30-50 um), was purified overnight prior to use, via magnetic stirring in a $2 \mathrm{M}$ nitric-acid solution, and was washed using triple-distilled pure water. SA was obtained from the Culture Collection and Research Center of biological bank of Korea. SA was maintained on tryptic soy agar slants, grown overnight on soy agar were continually cultured at $37^{\circ} \mathrm{C}, 24$ $\pm 2 \mathrm{~h}$ until a concentration of $10^{9} \mathrm{CFU} \mathrm{mL}^{-1}$ was reached. That was diluted to $3 \times 10^{2} \sim 5 \times 10^{2} \mathrm{CFU} / 1 \mathrm{ml}$ using $0.85 \% \mathrm{NaCl}$ electrolyte. The MCN working electrode was made using paste consisting of a mixture of $40 \mathrm{wt} \%$ carbon nanotube, $40 \mathrm{wt} \% \mathrm{Hg}$ (standard $1000 \mathrm{ppm}$ from Sigma), and $20 \mathrm{wt} \%$ reagent-grade mineral oil (New Jersey, USA, 1-800-01, Acro). The mixed paste was inserted into a 3-mm-diameter, 100mm-long catheter capillary and was stabilized with a 10-cycle scan from $1.0 \mathrm{~V}$ initial potential to $-1.0 \mathrm{~V}$ switching potential, at a $0.5 \mathrm{~V} / \mathrm{s}$ scan rate, in an electrolyte solution. Voltammetric assay was performed using the three-electrode system. A 3.0-mm-diameter graphite pencil electrode (GC) was prepared from common pencil lead (DongA XQ, ceramic, $60 \mathrm{~mm}, 0.9$ B). A 1.0-mm-diameter, 10-mm-long platinum metal wire working electrode was made, and $\mathrm{GC}$ was used as an $\mathrm{Ag} / \mathrm{AgCl} / \mathrm{KCl}$ reference and platinum counterelectrode. This three-electrode system was immersed in a solution of $1.0-\mathrm{mL}$ non-treated human blood serum as an electrolyte solution. All the experiments were performed at room temperature, without removing the oxygen. Human blood and patient sera were obtained from the National Blood Transfusion Research Institute.

\subsection{Cyclic properties of the GC and MGC}

Voltammetric reaction potentials depend on the anodic and cathodic electrotransfer activities; thus, the peak potential was sought in the 1.0-ml patient serum electrolyte. Three-electrode systems and the prepared sensor probes were directly inserted, after which multifid caning was performed on the commontype GC and metal Pt, and the MCN probes were compared using cyclic redox scan.

Figure 1. 
Figure 1 shows the real voltammograms of the common-type GC, Pt, and specified MGC probes, using the same blood sera and identical parameters. In the anodic scan, only probe oxidation with no signals appeared, but in the redox scan, two peaks appeared at 0.8 and $-0.2 \mathrm{~V}$ only in the MGC and GC electrodes, and Pt had only one peak. The histograms are shown in the figure. The peaks were $0.126 \times 10^{-}$ ${ }^{4} \mathrm{~A}$ MGC, $0.0992 \times 10^{-4} \mathrm{~A} \mathrm{GC}$, and $0.107 \times 10^{-4} \mathrm{~A}$ Pt. The immobilized-mercury effect is more sensitive than that of the common-type electrode. The results of this study can be applied to stripping voltammetry; thus, using the same cell systems, stripping voltammetric scan was performed on anodic and cathodic activities, and the parameters that were used were $-2.0 \mathrm{~V}$ initial potential, $2.0 \mathrm{~V}$ final potential, and $30 \mathrm{sec}$ accumulation time. Each voltammogram was obtained only for $0.047 \times 10^{-4} \mathrm{MGC}, 0.059 \times 10^{-4} \mathrm{~A} \mathrm{GC}$, and $0.05 \times 10^{-4} \mathrm{Pt}$ anodic, and not for the cathodic results. Moreover, the study results indicate that MGC is more sensitive than Pt and GC (results not shown). The peak potential was used for the diagnostic assay of SA for the human blood, then more expanded analytical properties were examined using square-wave stripping voltammetry.

\section{Results}

\subsection{Stripping voltammetric SA and positive patient sera using MCN}

Under optimum conditions, the diagnostic working ranges were examined using SA spiking in the healthy sera. In the 1.0-ml healthy plasma, sequential addition was performed with $240 \mathrm{sec}$ accumulation stripping time. Figure 2 shows the voltammetric results.

\section{Figure 2. (A) (B) (C)}

Under MCN probe, Fig. 2(A) shows the voltammetric anodic peak current for the cyclic (white curve) and stripping (black curve) voltammetric anodic scan. Here, a cyclic peak of $0.29 \times 10^{-4} \mathrm{~A}$ appeared at the $0.5 \mathrm{~V}$ reduction potential, which later increased to $0.076 \times 10^{-4} A$, where the linear curve was $y=0.0233 x+$ 0.00220 and $R^{2}=0.9613$, whose slope is more sensitive than that of stripping voltammetry. Moreover, the stripping slope was $\triangle x / \triangle y=0.0066$, the intercept was 0.0008 , and the statistic was $R^{2}=0.9856$. Both equations can be used for diagnostics. Thus, the more sensitive parameters of the accumulation effects were examined using MCN, and Fig. 2(B) shows the results, as follows: anodic peak high for time variation (-), $30-240 \mathrm{sec}$; and accumulation potential variation effects (- -$),-2.0$ to $-0.6 \mathrm{~V}$. Peak currents of $0.007-0.047 \times 10^{-4} \mathrm{~A}$ were obtained, and $240 \mathrm{sec}$ was the maximum accumulation time. Moreover, the stripping potential was varied from 0.0038 to $0.0289 \times 10^{-4} \mathrm{~A}$, and $-2.0 \mathrm{~V}$ was the maximum stripping potential. Thus, the $240 \mathrm{sec}$ accumulation time and $-2.0 \mathrm{~V}$ stripping potential were fixed. Under these conditions, the probe stability was examined via repeated stripping. Figure $3(\mathrm{C})$ shows the peak currents for the sera blank and 0.1-ml SA spiked voltammograms. The blank current was varied from 0.014 to $0.011 \times 10^{-4} \mathrm{~A}$, and the $0.1-\mathrm{ml} \mathrm{SA}$ spikes were $0.047-0.067 \times 10^{-4} \mathrm{~A}$. MCN is thus stable and can be used for diagnostics, with the final parameters fixed at $-2.0 \mathrm{~V}$ accumulation potential, $0.02 \mathrm{~V}$ amplitude, 
$25 \mathrm{~Hz}$ frequency, $0.01 \mathrm{~V}$ incremental potential, and $240 \mathrm{sec}$ accumulation time, using the conditions under which the analytical working ranges were examined.

\subsection{Diagnostic working ranges of SA}

Figure 3. (A) (B)

Under CV conditions, the linear working voltammetrics were sought at the 0.5 - to $4.0-\mathrm{ml}$ spikes. The reduction peak is shown in Fig. 3(A). Only a $0.2 \mathrm{~V}$ reduction peak appeared, and the first peak was that of the electrolyte blood serum. There were no signals at the $0.5-\mathrm{ml}$ spike, then a peak of $0.0013 \times 10^{-4} \mathrm{~A}$ was obtained at the $1-\mathrm{ml}$ spike, with $0.2 \mathrm{~V}$ reduction potential, which continually increased to a peak of $0.7921 \times 10-4 \mathrm{~A}$ at the $4-\mathrm{ml}$ spike, with a slop of $\mathrm{dx} / \mathrm{dy}=0.192$, an intercept of 0.012 , and a relative statistic of 0.9947 . The error percentage is shown at this curve. These results can be applied to diagnostics. Moreover, at the same spike range, a linear curve was obtained at seven points. Figure 3(B) shows the real voltammograms, where the first curve (for the electrolyte blood serum) is simple, then very small peaks were obtained at the 0.5 - and $1.0-\mathrm{ml}$ spikes, after which a $0.0044 \times 10^{-4} \mathrm{~A}$ peak was obtained at the $1.5-\mathrm{ml}$ spike. Moreover, at the $4-\mathrm{ml}$ spike, a peak of $0.021 \times 10^{-4} \mathrm{~A}$ was obtained, whose final curve was $y=0.005 x-0.002$ and whose statistic was $R^{2}=0.9649$. Under these conditions, the accumulation times that were used were 90 and $210 \mathrm{sec}$ for CV and SW stripping accumulation, respectively. As the SW effects were found to be much more sensitive than the CV effects, the former can be used for diagnostics. Under these conditions, the interference effects were calibrated using the standard addition methods, after which diagnostics was applied to the patients' sera.

\subsection{Patient Diagnosis}

Figure 4. (A) (B)

Under a sera solution, diagnostic application was performed on the patient plasma, via SW anodic stripping voltammetry. The contaminated serum sample was obtained from the National Blood Transfusion Research Institute. Figure 4(A) shows real voltammograms for 1.0-ml blood testing. The first curve represents the contaminated blood. In the $0.2 \mathrm{~V}$ anodic scan, a small peak current of $0.0072 \times 10^{-4} \mathrm{~A}$ was obtained, using $90 \mathrm{sec}$ accumulation stripping, then standard $S A$ was spiked to $0.5,1.0,1.5,2.0,2.5$, 3.0 , and $3.5 \mathrm{ml}$. The peak current linearly increased from 0.0113 to $0.0408 \times 10^{-4} \mathrm{~A}$. The regression equation was $y=0.006 x-0.006$, and the relative standard deviation was $R^{2}=0.9918$, which can be detected for 6.0-ul SA. Then more advanced tests were performed using a red corpuscle. Figure 4(B) shows the results of the use of the standard addition methods, where the first curve represents the red blood cells using optimum parameters. A peak current of $0.0009 \times 10^{-4} \mathrm{~A}$ was obtained, and 0.0021 $0.0055 \times 10^{-4} \mathrm{~A}$ peak currents were obtained at the 1-, 2-, and 3-ml SA spikes. The working equation was $\mathrm{y}=$ $0.0016 x-0.0008$, the statistic was $R^{2}=0.9922$, and the content was 0.8 ul. The results of the study can be used for diagnostics in any application.

\section{Conclusion}


A novel SA bioprobe was developed using an MCN sensor in non-treated human blood and patient sera. The immobilized-mercury effects were found to be more sensitive than those of the common probe type using cyclic voltammetry, where the following optimum analytical parameters were obtained: $-2.0 \mathrm{~V}$ accumulation potential, $0.02 \mathrm{~V}$ amplitude, $25 \mathrm{~Hz}$ frequency, $0.01 \mathrm{~V}$ incremental potential, and $240 \mathrm{sec}$ accumulation time. Under these conditions, the standard deviation of the $0.1-\mathrm{m}\left(15 \times 10^{2} \sim 25 \times 10^{2} \mathrm{CFU}\right) \mathrm{SA}$ was 0.0078 . The results of this study can be applied to diagnostic assay for positive patient sera and SA infections, and can be used in real-time medical diagnosis as well as in direct in-vivo monitoring.

\section{Declarations}

Funding, Not any funding support

Competing interests: none declared

Ethical approval, Approved by the university of SNUT review board

\section{Acknowledgements,}

Not any

\section{References}

1. Cremonesi P, Perez G, Pisoni G, Moroni P, Morandi S, Luzzana M, Brasca M, Castiglioni B, Detection of enterotoxigenic Staphylococcus aureus isolates in raw milk cheese, Lett Appl Microbiol 45 (2007), 586-591

2. Bernardo K, Fleer S, Pakulat N, Krut O, Hunger F, Kronke M (2002) Identification of Staphylococcus aureus exotoxins by combined sodium dodecyl sulfate gel electrophoresis and matrix-assisted laser desorption/ionization-time of flight mass spectrometry. Proteomics 2:740-746

3. Zorgani A, Essery SD, Al Madani O, Bentley AJ, James VS, Doris AC, MacKenzie JW, Keeling C, Rambaud J, Hilton CC, Blackwell DM, Weir, Busuttil A, Detection of pyrogenic toxins of Staphylococcus aureus in sudden infant death syndrome, FEMS Immunol Med Mic 25 (1999), 103108

4. SH, Huang HC, Wei YC, Lee, One step immunochromatographic assay for the detection of Staphylococcus aureus, Food Control 18 (2007) 893-897

5. Huang SH (2007) Gold nanoparticle-based immunochromatographic assay for the detection of Staphylococcus aureus. Sensor Actuat B-Chem 127:335-340

6. OGrady J, Lacey K, Glynn B, Smith TJ, Barry T, Maher M (2009) tm RNA a novel high copy number RNA diagnostic target its application for Staphylococcus aureus detection using real time NASBA. FEMS Microbiol Lett 301:218-223

7. Wada M, Lkhagvadorj E, Bian L, Wang C, Chiba Y, Nagata S, Shimizu T, Yamashiro Y, Asahara T, Nomoto K (2010) Quantitative reverse transcription-PCR assay for the rapid detection of methicillin- 
resistant Staphylococcus aureus. J Appl Microbiol 108:779-788

8. Cattoir V, Merabet L, Djibo N, Rioux C, Legrand P, Girou E, Lesprit P (2011) Clinical impact of a realtime PCR assay for rapid identification of Staphylococcus aureus and determination of methicillin resistance from positive blood cultures. Clin Microbiol Infec 17:425-431

9. Fox LK, Adams DS (2000) The Ability of the Enzyme-Linked Immunosorbent Assay to Detect Antibody against Staphylococcus aureus in Milk following Experimental Intramammary Infection. J Vet Med B 47:517-526

10. Zouharova M, Multiplex DRysanek (2008) PCR and RPLA Identification of Staphylococcus aureus Enterotoxigenic Strains From Bulk Tank Milk. Zoonoses Public Health 55:313-319

11. Ly SY (2006) Real-time Voltammetric Assay of Cadmium lons in Plant Tissue and Fish Brain Core. Bull Korean Chem Soc 27:10 pp.1613-1615

12. Ly SY (2008) Diagnosis of copper ions in vascular tracts using a fluorine doped carbon nanotube sensor. Talanta 74:1635-1641

13. Ly SY, Cho NS (2009) Diagnosis of human hepatitis B virus in non-treated blood by the bovine IgG DNA linked carbon nanotube biosensor. J Clin Virol 44:43-47

14. Ly SY, Lee JH (2009) Human-Urine Diabetes Assay and In Vivo Rat Bladder Assay Using a Fluorine Doped Carbon Nanotube Catheter Sensor. Ann Biomed Eng 37:2028-2033

\section{Figures}



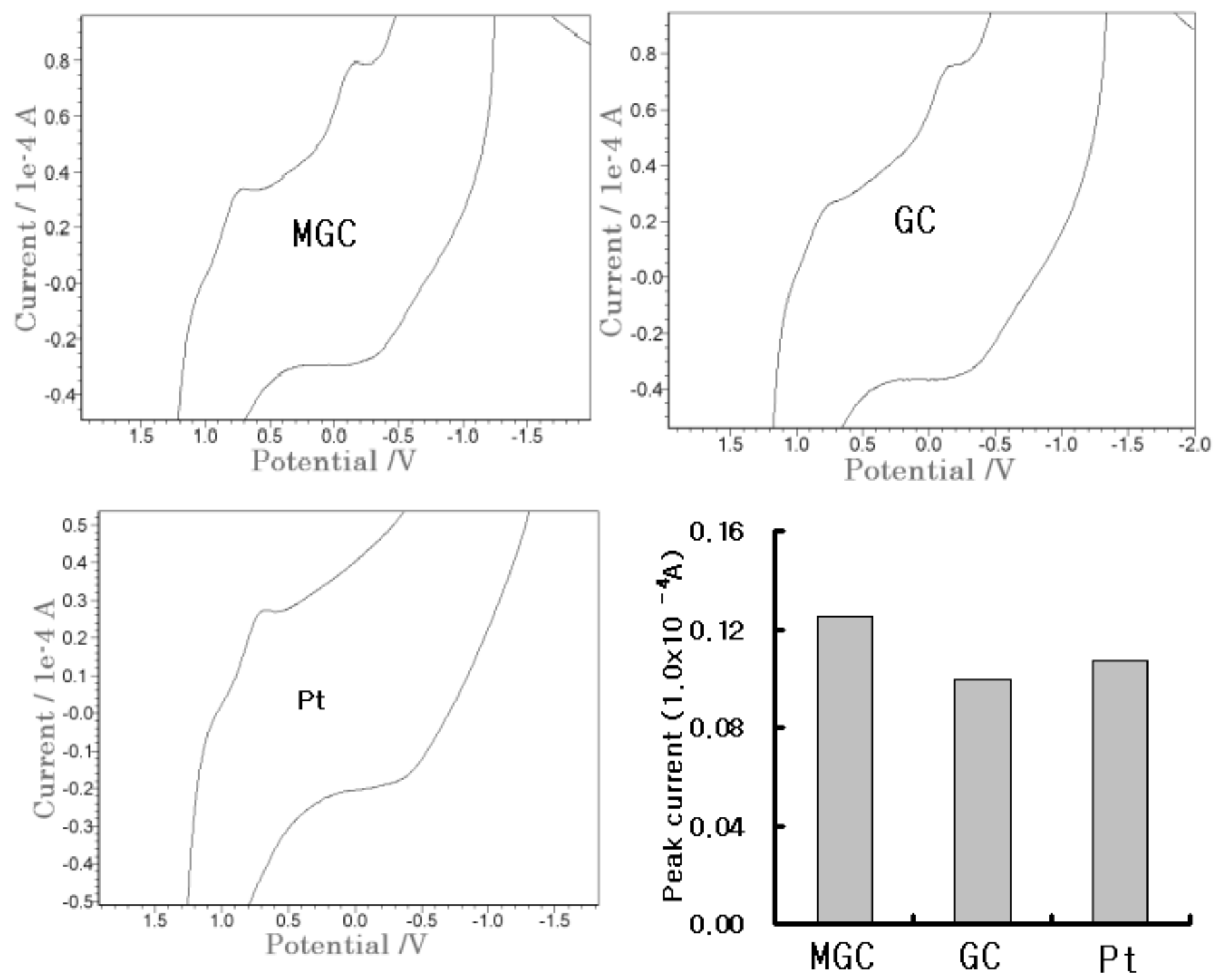

Figure 1

Cyclic voltammograms of the MGC, Pt, and GC probes in an SV 1.0-ml patient serum, with $30 \mathrm{sec}$ accumulation time, $-2.0 \mathrm{~V}$ initial potential, $2.0 \mathrm{~V}$ switching potential, and $0.1 \mathrm{~V} / \mathrm{s}$ scan rate, and the histograms of the oxidation peak current. 

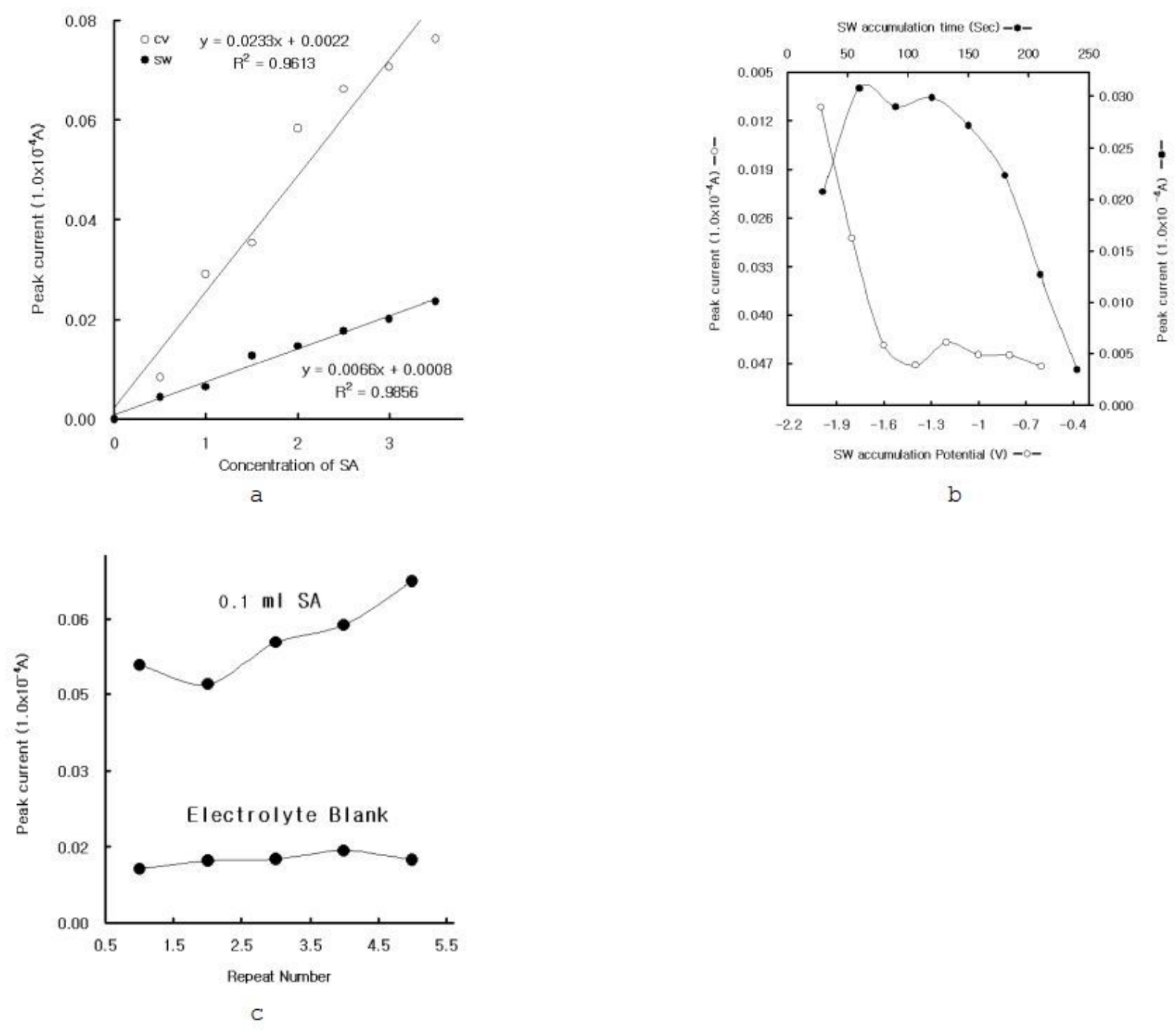

Figure 2

(A) Analytical working variations for the 0.5-, 1.0-, 1.5-, 2.0-, 2.5-, 3.0-, and 3.5-ul SA add in 1-ml serum using the MCN working electrode for CV -O- and SW -O-. (B) SW accumulation time variation for 30,60, $80,120,150,180,210$, and 240 sec - - -, and $S W$ accumulation potential variation for $-2.0,-1.8,-1,6,-1.4$, $-1.2,-1.0,-0.8$, and $-0.6 \mathrm{~V}-0-$. (C) Statistic MCN probe stability in serum blank and SA spike. Other parameters were used for the optimum conditions. 


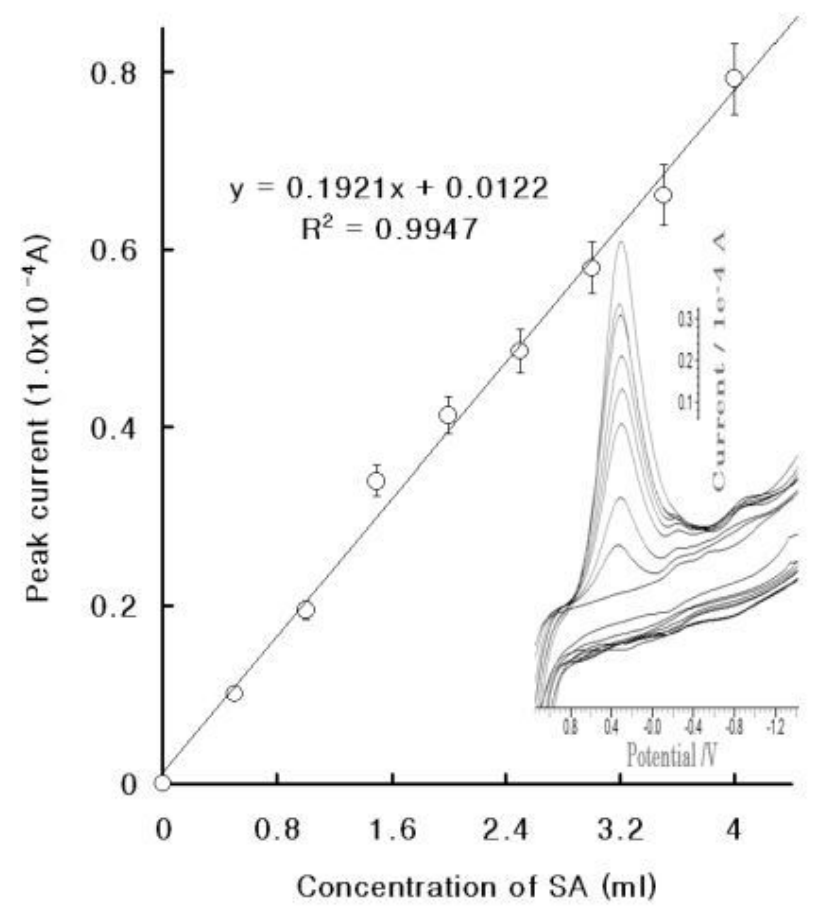

a

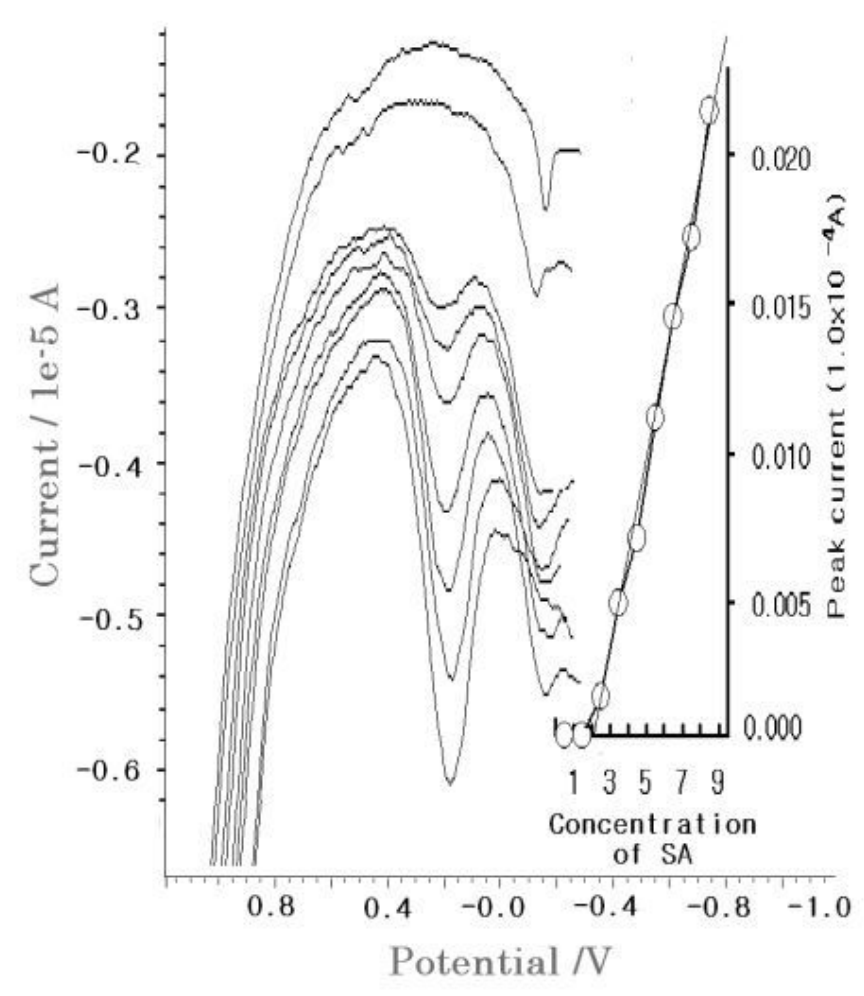

$\mathrm{b}$

Figure 3

(A) Cyclic linear voltammograms for the $0-, 0.5-, 1.0-, 1.5-, 2.0-, 2.5-, 3.0-, 3.5-$, and $4.0-\mathrm{ml}$ SA spikes. (B) Cathodic stripping voltametric working ranges of the $0.5-, 1.0-, 1.5-, 2.0-, 2.5-, 3.0-, 3.5-$, and $4.0-\mathrm{ml}$ SA spikes in a 1.0-ml non-treated blood serum with a pH of 7.0 and $0.02 \mathrm{~V} \mathrm{SW}$ amplitude, $75 \mathrm{~Hz} \mathrm{SW}$ frequency, $0.01 \mathrm{~V}$ increment potential, $-2.0 \mathrm{~V}$ accumulation potential, and $90 \mathrm{sec}(\mathrm{CV})$ and $210 \mathrm{sec}(\mathrm{SW})$ accumulation times. The optimum conditions were set for the other parameters. 


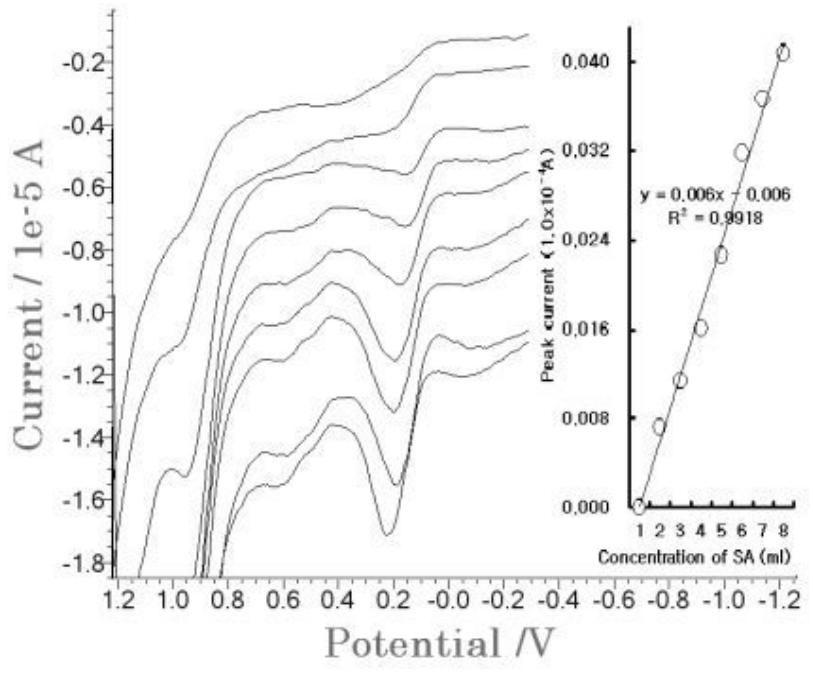

a

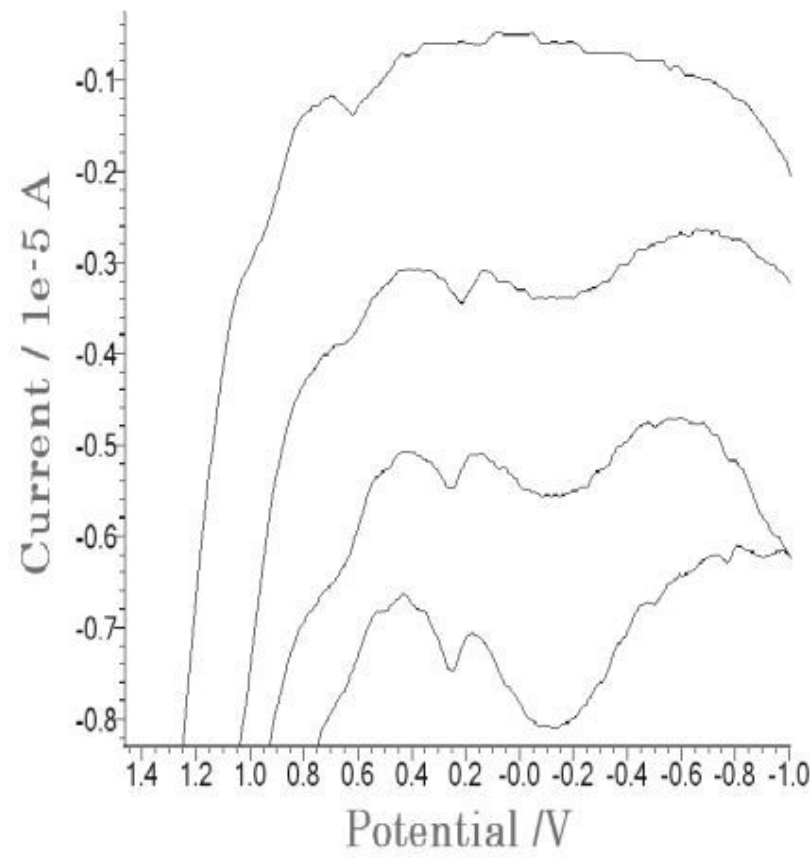

$\mathrm{b}$

Figure 4

Positive patient test. (A) Anodic stripping for the 1.0-ml patient sera, where the stripping conditions were $25 \mathrm{~Hz}$ frequency, $20 \mathrm{mV}$ amplitude, $-2.0 \mathrm{~V}$ accumulation potential, $100 \mathrm{sec}$ accumulation time, and $20 \mathrm{mV}$ increment potential. (B) The standard addition methods used on the patients' red cells, using the optimum SW conditions. 